\title{
Reconstrucción de la memoria colectiva: teatralidad y espacio público
}

\author{
Silvina Alejandra Díaz \\ CONICET - Universidad de Buenos Aires, Argentina \\ silvinadiazorban@yahoo.com.ar
}

Fecha de recepción: 29/03/2019. Fecha de aceptación: 02/05/2019.

\begin{abstract}
Resumen
Luego de la despolitización que, durante la crisis de 2001, alcanzó a todas las esferas de la sociedad argentina, tuvo lugar un redescubrimiento de la capacidad intervencionista y transformadora de la política y del rol fundamental de la cultura en la construcción del orden social. Lejos del nihilismo del "fin de lo social" (Baudrillard), el teatro sale a la calle física y metafóricamente, ocupa y resignifica el espacio público buscando asumir su potencialidad disidente y reconocerse como un canal privilegiado para la circulación, visibilización y producción de discursos. Nos referiremos a acciones teatrales e intervenciones urbanas -como las de Fin de un mundo y la Compañia de Funciones Patrióticas-, acontecimientos situados cuya dimensión política radica en la eficacia interpelante de la acción directa y en su vinculación con un territorio específico. Estas prácticas artísticas se presentan como una fuerza disruptora de la realidad cotidiana de la ciudad, y propician una articulación con los movimientos sociales para recuperar el sentido identitario del teatro en tanto acción de resistencia y fortalecimiento de los lazos comunitarios. Del mismo modo, y como efecto complementario, al intervenir en la esfera pública, la experiencia artística modifica sus propias convenciones y códigos.
\end{abstract}

\section{The Reconstruction of Collective Memory: Theatricality and the Public Space}

\begin{abstract}
After the depoliticization which, during the 2001 crisis, reached all spheres of Argentine society, the interventionist and transformative capacity of politics was rediscovered, as well as the fundamental role that culture has in the construction of the social order. Far from the nihilism of "the end of the Social" (Baudrillard), theatre goes out on the street physically and metaphorically, occupying and resignifying the public space, aiming to assume its dissident potential and to recognize itself as a privileged channel for the circulation, visibilization and production of discourse.
\end{abstract}

Palabras clave

Intervenciones urbanas Acción Espacio público Política Memoria Fin de un mundo Compañía de Funciones
Keywords

Urban interventions Action Public Space

Politics

Memory

Fin de un mundo

Compañía de Funciones 
In this essay, we will refer to different theatrical actions and urban interventions carried out by collectives such as Fin de un mundo and Compañia de Funciones Patrióticas. The political dimension of all these situated events lies in the interpellating efficiency of direct action and in their connection with a specific territory. These artistic practices appear as a force that disrupts the city's everyday reality. Also, they encourage an association with social movements in order to restore theatre's power to contribute in terms of identity building, operating as an act of resistance and strengthening community bonds. In the same way, and as a complementary effect, by intervening the public sphere, the art experience changes its own conventions and codes.

\section{Introducción}

Las coyunturas sociales, políticas y económicas desde la crisis de 2001 en Argentina estuvieron condicionadas no solo por los derroteros de la política local, sino también por las nuevas configuraciones culturales, oscilantes entre los signos universales de un proceso homogeneizador cada vez más fortalecido y los individuos, comunidades y formas artísticas que pugnan por ser reconocidos en su singularidad. La concepción de lo multicultural implica la coexistencia de diversos paradigmas culturales en el seno de la misma sociedad -en el sentido en que Marc Augé (1995) habla de "mundos contemporáneos"-y requiere, por lo tanto, nuevos modelos de análisis que modifiquen la visión estática que asociaba indefectiblemente la identidad con la tradición y el territorio, para reconocer que

el sentido de pertenencia a un grupo se desarrolla sobre la base de compartir un universo simbólico común (una representación colectiva que define una relación entre nosotros y los otros) que puede tener asiento sobre muy diversos fenómenos, no necesariamente territoriales o tradicionales. (Rosas Mantecón, 1993: 87).

En este contexto, y luego del proceso de despolitización que atravesó todas las esferas de la sociedad argentina durante la crisis socio- política, económica e institucional de 2001, tuvo lugar un redescubrimiento de la capacidad transformadora de la política y su generalización a esferas consideradas apolíticas -como la familia, la alimentación, la sexualidad, el cuerpo- (Hall, 2010). Del mismo modo, la cultura se convierte en escenario de debates y producción de legitimidad, en los que se torna crucial el replanteo de la cuestión de la identidad, el valor de lo público y el rol del arte en la configuración de un orden social.

Los novedosos usos del ámbito urbano y la acción de las agrupaciones sociales surgidas durante la crisis -manifestaciones, asambleas vecinales, piquetes- constituyen una respuesta a la privatización de un sector del espacio público llevada a cabo por el programa neoliberal de la década del 90, que modificó el aspecto de la ciudad, alterando hábitos y formas de vida (Lobeto- Circosta: 2014: 18).

En la actualidad, y como reacción a las políticas de ajuste, endeudamiento externo y negación de la memoria histórica, las agrupaciones de teatro callejero, las acciones e instalaciones artísticas, las intervenciones y performances urbanas propician una mayor articulación con los movimientos sociales en vistas a recuperar el sentido político, cultural e identitario. Sus protagonistas, que pueden considerarse entonces verdaderos activistas culturales en tanto recurren a la acción directa e interpelante, redefinen el espacio público como un ámbito de construcción de la memoria y se relacionan con un territorio específico, que aparece como lugar de resistencia y creación de relaciones sociales (Svampa: 2008: 77-78). 


\section{Activismo artístico y territorialidad}

Podríamos definir a la intervención urbana como una acción artística original que se desarrolla en el espacio público, que no responde a estructuras o modelos prefijados, sino a la subjetividad de un artista o un grupo de artistas y busca generar una reacción en el espectador.

La utilización de ámbitos urbanos, no teatrales, condicionados desde el punto de vista arquitectónico, urbanístico y de los usos sociales, implica que no sufren modificaciones a los fines estéticos, sino que son valorados en su dramaticidad y en su carácter de espacio de encuentro. Ocuparlos y resignificarlos supone asumir la potencia disidente del teatro, de las acciones y los "cuerpos en movimiento frente a otros cuerpos vivientes que deben ser movilizados" (Rancière: 2010: 11), que a su vez se dejan atravesar y condicionar por las variables del espacio público.

Las intervenciones escénicas, las instalaciones, las acciones y performances urbanas se presentan como un "gesto de desacato", una fuerza disruptiva del devenir de la experiencia cotidiana (Richard, 2007), y se caracterizan por poseer

estructuras operacionales que se mantienen abiertas y cuyos materiales (aconteceres biográficos, transcursos comunitarios) permanecen inconclusos, garantizando así la no finitud del mensaje artístico para que el espectador intervenga en la obra y complete su plural de significaciones heterogéneas y diseminadas. (Richard, 2007: 17).

Es justamente su postulación de "una espacialidad alternativa a los recintos de arte cercados por la institución", su dimensión procesual y su carácter abierto lo que las torna más fructíferas para expresar miradas innovadoras y proponer una resemantización creativa de "microterritorios de experiencia cotidiana". (ibidem).

Por otro lado, mientras Patrice Pavis define a la instalación a partir de la confluencia de diversos elementos artísticos "con exclusión, de actores o performes vivos" (2003: 248), Toni Mulet y Jesús Cabañero (2008) aluden a instalaciones performáticas que incluyen a las experiencias teatrales entre la diversidad de actividades y disciplinas que pueden formar parte de una ellas: la arquitectura, el diseño, el happening, las proyecciones multimedia, los jardines urbanos, el bricolage, el land art. Sin embargo, las definiciones coinciden en que la instalación propicia el itinerario, la trayectoria libre o guiada de los espectadores, y que esto "denota un lugar de deslizamiento de la práctica arquitectónica, revelando maneras de ver la experiencia del usuario y del espacio como una forma de arte en sí mismo." (Mulet y Cabañero, 2008: 2). Los autores estacan además su imposibilidad de ser trasladadas a un lugar diverso al de su propia cartografía, por cuanto el marco se convierte una parte esencial de la obra de arte.

En una concepción similar, en su libro Instalaciones, Josu Larrañaga observa que, en este tipo de producciones:

el espacio deja de ser soporte de la obra para volverse parte prioritaria de la misma, funcionando a la manera de un tejido intertextual. El espacio no es ya un recipiente nuevo en el cual se depositan los objetos artísticos, sino que debe leerse como un conjunto de mecanismos dispuestos por el autor que necesitan ser activados por el espectador para comenzar a funcionar. En este sentido, el artista instalador propondría una zona abierta de interacción, de intercambio y de diálogo con el espectador quien -en definitiva- será aquel que otorgue contenido a la obra en el acto mismo de recorrerla. (2006: 2). 
Si, como venimos afirmando, las prácticas escénicas urbanas resignifican, por un lado, la concepción de lo público y, por otro, el vínculo entre arte y política, enfatizando el poder de transformación social del arte, habría que preguntarse cómo se entreteje la subjetividad artística con las instancias urbanas, cómo se redefine el lugar del autor, del actor y del espectador y en qué consiste la tarea del performer en relación con el actor tradicional. Recordemos que el término performer subraya la acción realizada por el actor, que obra en su propio nombre, en contraste con la representación mimética de un papel, y se encuentra física y psíquicamente presente ante el espectador. (Pavis, 1994: 150). En las intervenciones escénicas urbanas, la disolución del personaje implica también la disolución del espectáculo, aún cuando pueda mantenerse una mínima estructura representacional.

Fin de un mundo (FUNO) es un colectivo independiente de acción urbana, creado en 2012, que lleva a cabo performances, acciones artísticas e intervenciones en diversos puntos de la ciudad de Buenos Aires con la intención de denunciar problemáticas sociales acuciantes. El grupo está integrado, entre otros artistas, por Carolina Wajnerman, Laura Mik, Galileo Bodoc, Lucila Infantino, a quienes se suman numerosos activistas y performers que responden a las convocatorias para formar parte de las distintas acciones artísticas. Los miembros del grupo -artistas independientes autoconvocados- conciben al arte como una herramienta de concientización, resistencia y lucha. Como sostienen en su Manifiesto Proyecto Fin de un mundo 10/52:

Nuestro propósito es tomar las riendas del arte en un presente global de escepticismo y frivolidad. Es apropiarnos de nuestra ciudad, de nuestras calles, de nuestras herramientas creativas. Nos enfocamos en el proceso continuo de construcción de identidad y paralelamente en la formulación de intervenciones. Generar una intervención artística pacífica pero de alto impacto.

Internamente, el grupo está organizado en distintas áreas de trabajo interrelacionadas -puesta en escena, vestuario, registros audiovisuales, comunicación y difusión, aspectos técnicos- según estructuras de participación flexibles, no jerárquicas, proclives al horizontalismo, a partir de la autogestión como forma de producción.

Proyecto 10/52, el primer trabajo de FUNO, realizado en ocasión del 520 aniversario de la Conquista de América, consistió en una acción multidisciplinaria desplegada en el trayecto comprendido desde Callao y Corrientes hasta el Obelisco. En una carabela confeccionada por artistas plásticos sobre la estructura de una camioneta se representaba a diversos personajes relacionados con la conquista española, poniendo el acento, desde lo iconográfico, en la idea del avasallamiento de las culturas originarias.

Desde 2014 realizan Puentes, una intervención en el Puente Pueyrredón con música en vivo, canciones compuestas por los integrantes del colectivo y la representación de escenas breves. Tanto Proyecto 10/52 como Puentes responden a una de las líneas de trabajo del grupo, que mantiene elementos vinculados con la estética teatral: una estructura escénica y un texto dramático de Liliana Bodoc y de Vicente Zito Lema respectivamente, como punto de partida del trabajo creativo, personajes y situaciones con un mínimo desarrollo dramático. Una serie de trabajos, que también pueden incluirse en esta línea -interrupciones artísticas en conferencias académicas, intervenciones ecologistas y montajes colectivos en festivales- adoptaron la modalidad del teatro invisible, tal como lo plantea Augusto Boal. En OAMA (Organización de Amigos de América) (2016), una acción realizada en ocasión del bicentenario de la independencia argentina -que tuvo una notable difusión a partir de que fuera llevada a las redes sociales- los performers y sus invitados intervenían en dos actos oficiales llevados a cabo en la ciudad de Buenos Aires, encarnando distintos personajes y representando situaciones escénicas que buscaban ocultar su carácter ficcional. Los artistas que 
respondieron a la convocatoria fueron agrupados según los roles: una familia tipo, la comisión directiva de la organización ficticia, los periodistas que cubrirían el evento, la juventud de OAMA y su taller de meditación, un coro góspel, un grupo de pericón y uno de porristas.

La otra modalidad de trabajo del colectivo revela una limitación de recursos teatrales y una conexión más directa entre el hecho artístico y la coyuntura política -lo que conforma uno de sus procedimientos compositivos fundamentales-, como así también una apelación inmediata al espectador, a quien se involucra de diversos modos en el acto artístico. Pensamos, por ejemplo, en las sorpresivas apariciones de mujeres encadenadas paseadas por sus hombres, que condensa en una imagen brutal los abusos de la sociedad patriarcal (Perras), como así también en PROmbies, sujetos con globos y cartelitos amarillos en la cabeza -en una clara parodia a la estética publicitaria del gobierno- que irrumpían en la rutina de los transeúntes y de los pasajeros del subterráneo generando comicidad, asombro o indignación.

Desde 2013, cuando presentaron la intervención Memoria y canto para volver, participan en la Marcha por la Memoria, el 24 de marzo de cada año, fecha que evoca el golpe de Estado de 1976 que diera comienzo a la etapa más cruenta de la historia argentina. En estas producciones, enmarcadas en la última modalidad a la que se hacíamos referencia, se produce el desmontaje de la idea de representación y ficcionalidad para poner el acento en lo efímero y lo inacabado de la producción más que en la obra de arte como producto. (Pavis). El cuerpo mismo del performer se convierte en el relato, su acción deviene significante y no medio para significar algo. Esta "posibilidad discursiva del cuerpo como acción" supone "la reelaboración de la idea de acontecimiento como posibilidad abierta" y con ello "una manera de volver a pensar la relación entre experiencia y representación (relato) como tensión constitutiva de la subjetividad." (Barría Jara, 2011: 117). La performance no constituye entonces una mera reflexión sobre el cuerpo sino que pone en juego una política del cuerpo, en la que éste "viene a ser un dispositivo que altera la noción de espectacularidad a la que está asociada convencionalmente la idea de teatralidad". (2011:112).

En 2014, el grupo reformuló su propuesta en Memoria y canto para volver II, mientras que al año siguiente dieron a conocer Radio Funo. Memoria y canto III, conformado por una serie de canciones de protesta y acciones coreográficas en las que el cuerpo, antes torturado, desaparecido, doblegado, se reconoce como símbolo de la lucha por la libertad.

Las intervenciones de 2015, 2016, 2017 y 2018 realizaron el trayecto que va desde Plaza Congreso hasta Plaza de Mayo en caravanas festivas que incluían acciones artísticas diseñadas a partir de estructuras coreográficas simples y música en vivo. En estas últimas versiones, el grupo convocó, a través de las redes sociales, a todo aquel que quisiera formar parte del acontecimiento, para lo cual debía asistir a ensayos abiertos, a los que se invitaba también al público con la modalidad de colaboración a la gorra. En 2018, alrededor de doscientas personas formaron parte del evento artístico portando carteles con la consigna Nunca más. Organizados en diversos grupos, los performers generaban su propio espacio para llevar a cabo su acción y se sumaban luego a los manifestantes, convirtiendo a la práctica artística en una verdadera experiencia colectiva.

Una gran cantidad de artistas respondió también a la "convocatoria a marchar con Fin de un Mundo" el 24 de marzo de 2019. Con la Marcha por la Memoria como marco del acontecimiento artístico se presentó Radio FUNO Vol 7, bajo el lema "Aquí se respira lucha: 7 veces latimos, 30000 estamos de pie. Un torbellino de cigarras arrasando al olvido. Nuestra danza crece sembrando memoria, verdad y justicia". 
Lejos de la actitud desencantada de cierta retórica postmodernista, el carácter festivo de estas performances adquiere una importancia fundamental para subrayar la voluntad de resistencia y la empatía que se produce con el espectador- participante, con quien establecen una comunicación física, sensorial y emocional. Se pretende movilizarlo profundamente, convertirlo en un sujeto activo que, junto con el performer, construya la acción y el conocimiento.

Ciertamente, no puede negarse un matiz utópico en la ideología de estas agrupaciones, no ya en la creencia de un arte transformador a nivel individual -objetivo que, por cierto, guiara las búsquedas artísticas de grandes maestros y reformadores del teatro-, sino en la idea de que esta transformación pueda contribuir a proclamar el fin de un mundo y a configurar, tal como creía Brecht, una sociedad más justa y equitativa. Debe reconocerse, sin embargo, una notable eficacia política -sin identificaciones partidistas- en su capacidad de convocar al encuentro y tomar las calles para visibilizar los conflictos sociales, invitando a la reflexión y la participación. A propósito de esto, Galo, performery uno de los coordinadores de las intervenciones, sintetiza la ideología de estos colectivos:

El arte transforma de manera muy concreta. No es una cesión metafórica. Quien lo vive de adentro se transforma. Y quien lo ve también se transforma. De alguna manera, cambiar el pequeño mundo que nos rodea es nuestra meta como artistas". Y, con respecto a las diferencias políticas, señala: "Lo que realmente intentamos es no entrar en una discusión ideológica dentro de colectivo, seleccionar aquellas cosas que tenemos en común, saber que hay un enemigo gigante que es el imperialismo que nos aplasta a todos por igual (...). Entonces hacemos política desde el cuerpo, la poesía, el arte, la música, y esa es nuestra manera de discutir. (www.anred.org./p55019)

Pero su eficacia radica también, como sucede con las formas posdramáticas, en "plantear desde perspectivas inhabituales ideologemas sociales y culturales" que nos permiten "seguir reflexionando críticamente sobre nosotros mismos como comunidad y como individuos inmersos en los atribulados tiempos posmodernos." (Trastoy, 2017: 22).

Frente a la concepción política imperante del ámbito público asociado al tránsito, al esparcimiento, al disfrute del ocio, y de la ciudad como una atractiva urbe, FUNO propone la idea de un lugar de encuentro y redefinición, de confrontación y debate, de desmontaje de la simbología que ordena a la sociedad a partir de la acción, del lenguaje y la poesía, de la danza y la música. La calle se revela, entonces, como un sitio en tensión, donde se confrontan los relatos conservadores y las diferentes voces que, desde el arte, pretenden arrebatar a las políticas institucionales el monopolio del recuerdo y el olvido. El espacio público "es por definición un espacio en conflicto donde la puja por la visibilización es inherente a las producciones y donde la memoria de lo que 'debe' ser recordado también es un territorio de disputa." (Lobeto- Circosta, 2014: 22). 


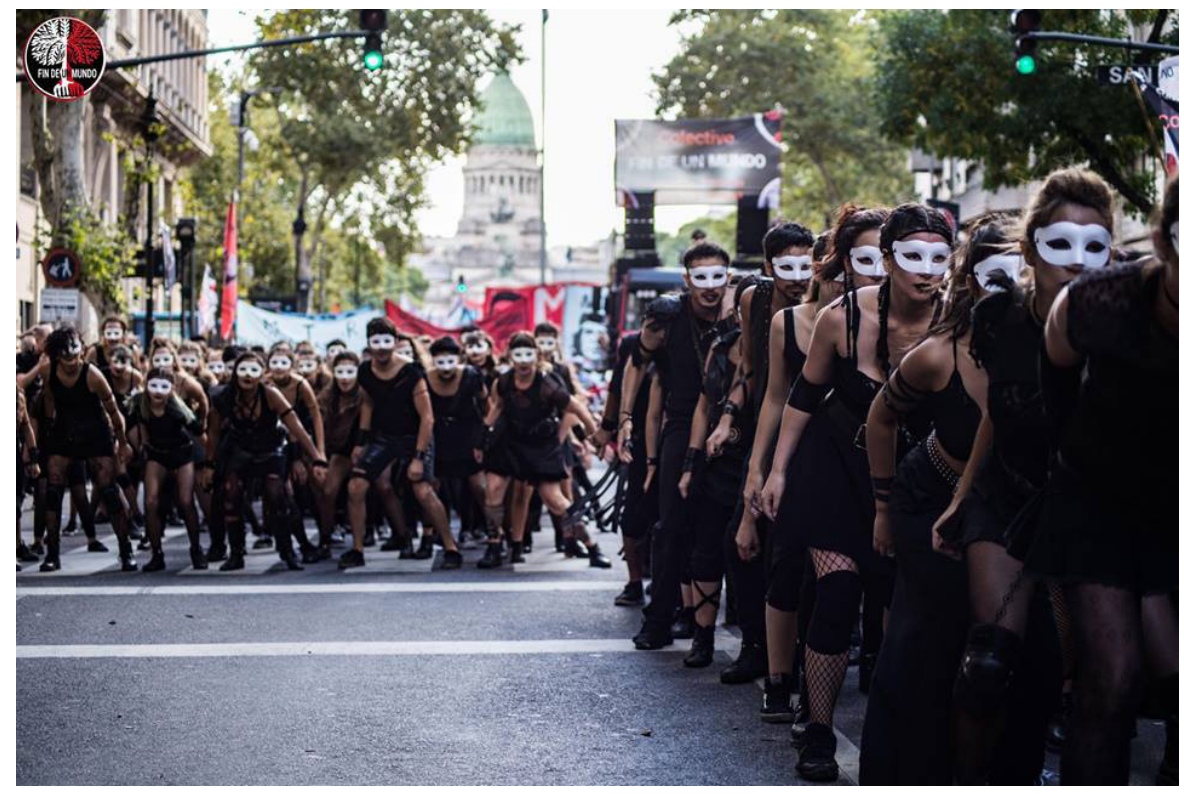

Fotografías tomadas por Círculo Foco del colectivo Fin de un Mundo, 24 de marzo de 2019.

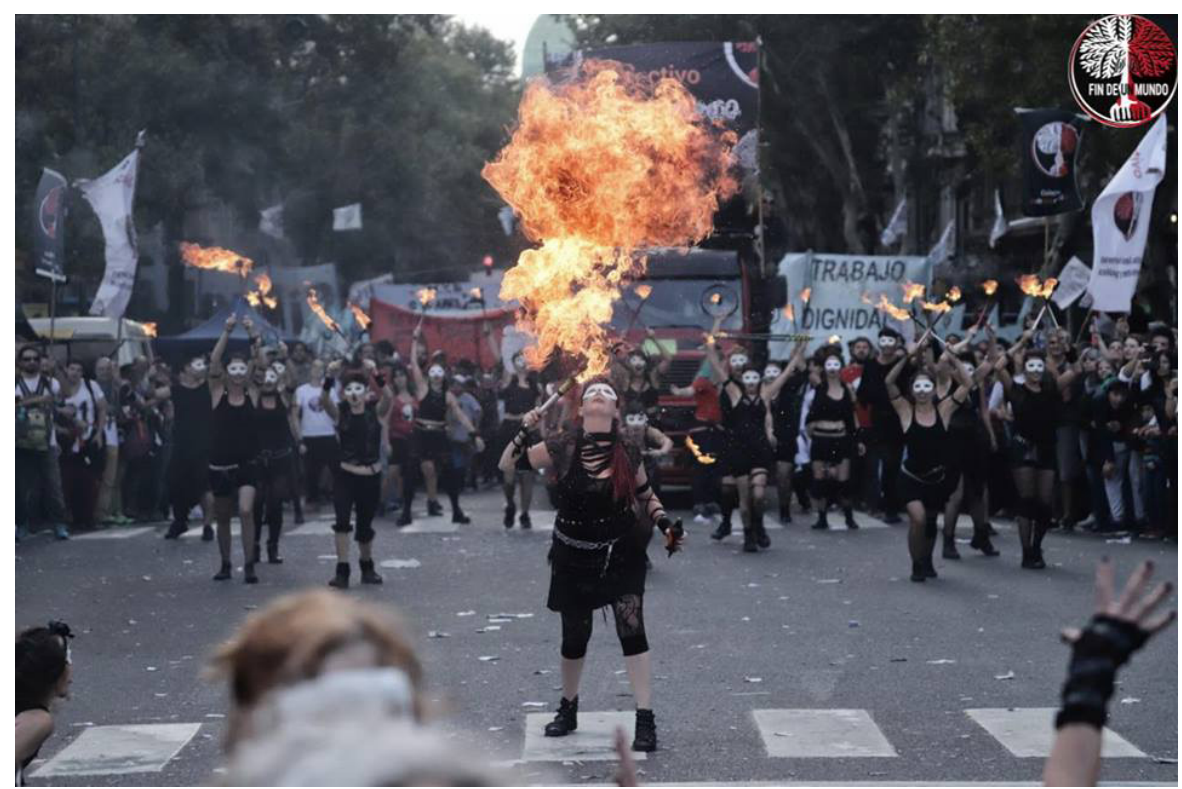

\section{Experiencias urbanas de memoria colectiva}

Creada en 2008, la Compañia de Funciones Patrióticas y el colectivo Corda/ Doberti ${ }^{1}$ se define como un grupo de activismo, teatro y performance que indaga sobre el sentimiento patrio desde una perspectiva crítica. Su nombre alude irónicamente a las representaciones teatrales organizadas para conmemorar fechas patrias y eventos políticos o militares. Las producciones del grupo se han presentado en salas de teatro alternativo, oficial o comercial, en ámbitos de arte contemporáneo -como Fundación PROA- y en centros culturales universitarios.

1. Integran el grupo Laura Lina, María Lorea, Daniel Miranda, Felipe Rubio, Martín Seijo, Virginia Corda, María Paula Doberti y Nora Iniesta, además de los performers invitados que se suman en cada ocasión. Por su parte, Virginia Corda y María Paula Doberti son artistas visuales que trabajan en intervenciones urbanas desde 2002. En el Grupo de Arte Callejero Periferia investigaron la relación entre historia, memoria y espacio público y luego, como colectivo, generaron acciones performáticas, entre las que se destaca Proyecto Manifestar Historia. 
Sus Relatos Situados ${ }^{2}$ reúnen una serie de acciones performáticas realizadas en distintas esquinas de la ciudad de Buenos Aires como parte del proyecto Manifestar historia. Esta idea de la obra de arte como itinerario, en permanente diálogo con la historia, con las coyunturas políticas y culturales, convierte a la ciudad "en un espacio que recoge el sentido del viaje y que permanentemente es resignificado por los vecinos, transeúntes y público ocasional", por lo que el artista aparece como el "recolector y traductor de las vivencias y necesidades de la comunidad". (Lobeto- Circosta, 2014: 20). Más allá de que el itinerario que propone cada uno de estos eventos esté diseñado de antemano, el concurrente se desplaza siguiendo su propio ritmo e intereses, deteniéndose más o menos tiempo en los puntos estipulados. La concepción del "arte de la flânerie" que Benjamin desarrolla pensando en el surrealismo (1969), condensa dos ideas fundamentales que pueden ponerse en juego a la hora de pensar la actividad del espectador- participante de las instalaciones y las intervenciones artísticas urbanas: la noción de un sujeto que otorga nuevos sentidos a la vida en la ciudad a partir de vagabundear por sus márgenes, y la definición de la tarea del flâneur como la detención del flujo continuo y codificado de sus significantes, para percibir el detalle oculto en los objetos y recrear en ellos la totalidad de la cultura desde su propia mirada. En concordancia con esto, el concepto de Debord de "la deriva" (1958) alude a un individuo que se deja fluir por la ciudad, que la recorre y experimenta a partir de sensaciones, apetencias y flujos de deseos que se plasman en cartografías.

Podría aludirse, como un antecedente de esta modalidad creativa, al Festival Estudio Abierto organizado por la Secretaría de Cultura del Gobierno de la Ciudad, entre 2000 y 2006 que proponía, como modo de acercamiento a la obra artística, diversos recorridos por distintas zonas abiertas de la ciudad, como así también en centros de exposiciones, museos y estudios de artistas, con la guía de sus creadores. En estos eventos, ideados en un comienzo en torno a la plástica y a los que se incorporaron luego intervenciones, teatro, danza, música, lecturas de poemas, debates abiertos, la ciudad se convertía en el soporte del acontecimiento y en el relato mismo.

Relato Situado. Acción de memoria urbana (2015) se propone la reconstrucción de la memoria desde una mirada diversa de la que postula el discurso institucional -monumentos, memoriales, museos y relatos oficiales-. Lejos de esa enunciación anónima y abstracta, que unifica y totaliza la experiencia del pasado, se trata de reconocer su enorme complejidad y sus variables desde el aporte colectivo de relatos fragmentados: referencias históricas, fuentes bibliográficas diversas, recuerdos personales. Estas narraciones, basadas en datos reales, testimoniales, ficcionales o construidos, conforman una red de múltiples puntos de vista, manifestados desde la experiencia, la vivencia y las emociones de personas anónimas en una circunstancia histórica y territorial concreta. Con respecto a esto, en el programa de mano de la intervención puede leerse: "Los lugares de la memoria se presentan insondables y efímeros, pero solo desde esta fragilidad es posible construir una historia común". Se apela de esta manera a la memoria del espectador, a su compromiso y, en definitiva, a su accionar como ser social.

Antes de comenzar el recorrido a lo largo de ocho cuadras de la ciudad, se asignan distintas funciones a los asistentes -pegar afiches, sacar fotos, filmar, tomar notas, dibujar-, que adquieren así un rol análogo al de los performers en la construcción de la acción. En una esquina los actores comparten sus recuerdos personales, que aparecen ligados de diversos modos al devenir político del país, e instan a los otros participantes a explorar en sus propias vivencias. Frente al Ministerio de Salud, que ostenta el relieve del rostro de Eva Perón en las caras norte y sur del edificio, realizados por los artistas Alejandro Mármol y Daniel Santoro respectivamente, se asiste a la lectura del discurso de la primera dama en ocasión de su renunciamiento a la vice- presidencia de la Nación, el 31 de agosto de 1951. Luego, otro actor aporta
2. Además de los que mencionamos en este trabajo, otros Relatos Situados que presentó la Compañía fueron: La memoria en el Centro (2016), Lanús tiene memoria (2017), Memoria de Campo de Mayo (2018), Memoria de la Reforma (2018) y Avellaneda tiene memoria (2018). 
referencias sobre la Avenida 9 de Julio y el Obelisco. En otro momento, se alude al bombardeo de 1955 mientras se lee un escrito de Agustín Tosco, nieto del reconocido dirigente sindical marxista y miembro de la CGT. Con la intención de evocar imágenes de Evita presentes en crónicas históricas, ficcionales y en el imaginario de los argentinos, se representa un fragmento de Eva Perón de Copi, que finaliza con su abrazo al personaje de La Patria.

Durante el trayecto, que incluye una serie de situaciones y acciones que surgen y desaparecen como destellos de la memoria -de las cuales mencionamos solo algunas-, se intercambian impresiones y recuerdos que los concurrentes registran en distintos soportes: anotaciones en papel, dibujos, fotografías, filmaciones.

En otra reconocida intervención urbana del colectivo, Relato Situado. Una topografía de la memoria (Performers: Virginia Corda, María Paula Doberti, María Fernández Lorea, Julieta Gibelli, Laura Lina, Ezequiel Lozano, Felipe Rubio, Martín Seijo, Martín Urruty. Compañía de Funciones Patrióticas, 2016/2017). El recorrido por las baldosas conmemorativas de Almagro se retomó en Relato situado. Los sentidos de la memoria, 2018/2019), donde se propuso un recorrido por el barrio porteño de Almagro siguiendo las baldosas de la memoria, diseñadas, realizadas y colocadas por Barrios $x$ Memoria y Justicia para señalar los lugares donde vivieron o trabajaron los militantes secuestrados y desaparecidos por el terrorismo de Estado. Pero, lejos de poner el acento en la información histórica, la evocación de sus historias de vida prioriza el aspecto emocional, la necesidad colectiva y afectiva de recordar.

En cada baldosa se realiza una intervención desplegada en una acción o una pequeña situación teatral o musical: colocar flores, leer un texto grupalmente, recitar poemas, tocar la guitarra, cantar, delinear en una tela o en la vereda la silueta de un cuerpo. La caminata se inicia en la sala El Umbral, desde donde salen los grupos guiados por los actores. El asistente adquiere, también aquí, un rol sumamente activo por cuanto, además de su compromiso físico, debe llevar a cabo la tarea que le fue asignada, como así también aportar datos, comentar sus vivencias y registrar por escrito, en el plano del barrio, sus impresiones.

Como en los casos anteriores, la idea de trayecto define no solo la estructura del hecho creativo, sino también su propósito: mostrarse como un proceso abierto, en permanente construcción, que invita a recorrer un espacio concreto, a ocuparlo físicamente, a identificarse emotivamente con las personas conmemoradas. El camino adquiere entonces -quizás de una manera más evidente que en otras intervenciones- un carácter ceremonial y comunitario, semejante al de una peregrinación, donde prima el silencio respetuoso y la empatía, puesto que el recuerdo deviene en una memoria viva. En este sentido, el recorrido conjunto por un territorio específico, con un entorno y una historia en común, pone de relieve las características de un arte relacional construido sobre la base de los vínculos humanos, en el aquí y ahora, que toma como horizonte "la esfera de las interacciones humanas y su contexto social, más que la afirmación de un espacio simbólico, autónomo y privado". (Bourriaud, 2017: 13).

En Relato Situado. Los barrios tienen memoria 2018, la propuesta se diversificó en cuatro itinerarios: dos de ellos en Almagro -Mujeres construyen memoria y Los sentidos de la memoria-, uno en el barrio de La Paternal y el último en el de Villa Crespo, a partir del mismo objetivo que se persiguió desde un comienzo: homenajear a las víctimas de la dictadura, recuperando el pasado para ponerlo en relación con nuestro presente.

En 2019, se repuso Mujeres construyen memoria, que en la jornada del 24 de marzo formó parte del evento Relato Situado. Los barrios tienen memoria 2019 en el que 
intervinieron tres colectivos teatrales en trayectos simultáneos: La Compañía de Funciones Patrióticas Corda-Doberti en el barrio de Almagro, La Compañía de Ataque en el de Chacarita y Avive Compañía de Inventarios en el de Villa Crespo.

Mujeres construyen memoria (Compañía de Funciones Patrióticas. Artivistas: Marilú Diz, Catalina Lescano, Noelia Prieto. Marín Seijo, Martín Urruty. Dirección: Martín Seijo. 2019) propone una cartografía de la violencia de género en el barrio desde la concepción de la memoria como palimpsesto; los recuerdos se borran, se reescriben, se actualizan, por cuanto la memoria no es otra cosa que una construcción cultural, dinámica, en permanente transformación.

Se busca deconstruir y reconstruir distintos registros del abuso físico y emocional, para evidenciar los mecanismos de dominación doméstica y social que el patriarcado ha ejercido tradicionalmente contra la mujer, pero evocando también otras modalidades de sometimiento ejercidas sobre hombres y mujeres por el poder político, la religión o los patrones culturales.

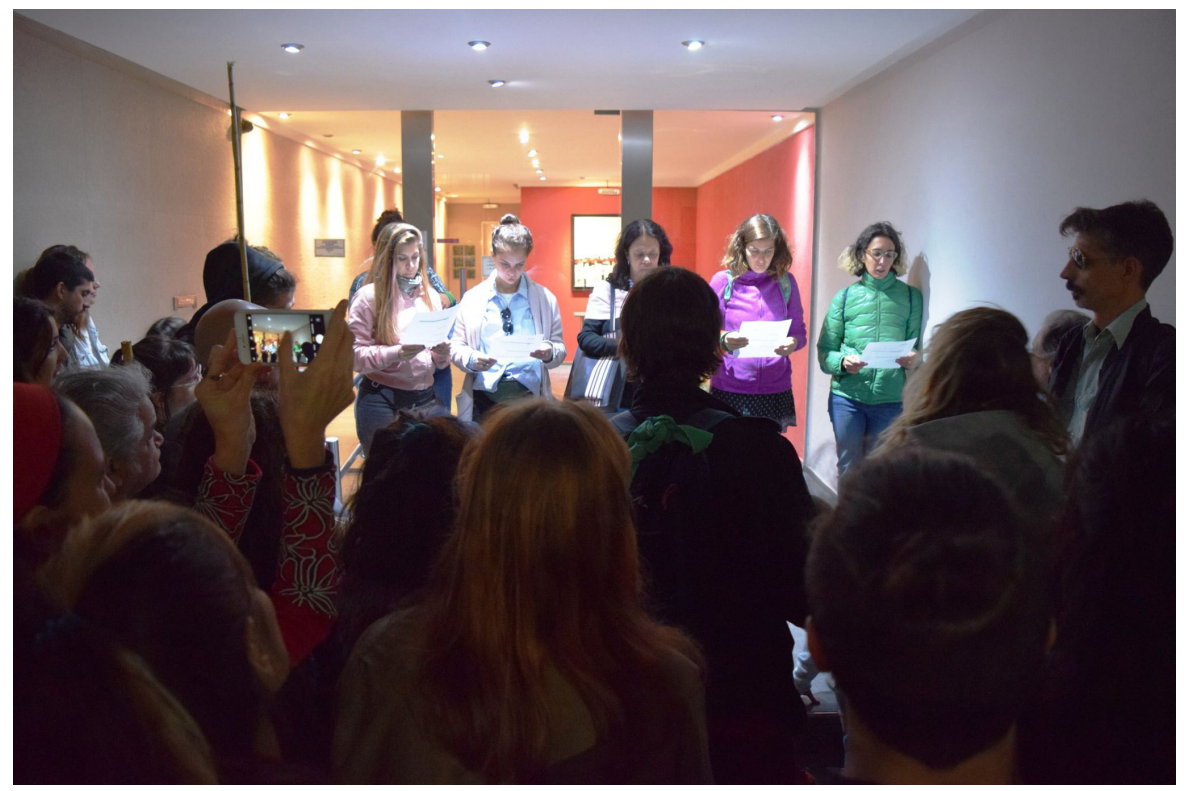

Mujeres construyen memoria, como parte del evento Los barrios tiene Memoria 2019, el 24 de marzo de 2019. Fotografía tomada por la Compañía Funciones Patrióticas.

Guiados por los autodenominados artivistas, los asistentes reconocen los lugares en que una mujer fue desaparecida por la dictadura militar o víctima de violencia de género en cualquiera de sus formas. Lo que se pretende es adentrarse en la dimensión intimista de acontecimientos traumáticos -colectivos o individuales- para construir un camino de información y de denuncia a través del arte. Cada uno de esos sitios se torna significativo gracias a una intervención que evoca el episodio desde una dimensión profundamente conmovedora. Las palabras, la música y las canciones -creadas por los integrantes de la Compañía- apuntan a despertar la conciencia del asistente, como la que expresa: "Es el Estado, es el Estado que tapa, que oculta, que viola, que mata. (...) Es mi memoria, es tu memoria, que late, que siente, que busca, que salva. Hacen falta más baldosas, hacen falta más pañuelos, hace falta más". Del mismo modo se ponen en evidencia, a partir de la parodia y la ridiculización, estereotipos de violencia y dominación presentes en el tango como música nacional. Se alude, por ejemplo, a la letra de La Morocha, de Ángel Villoldo: "Soy la morocha argentina, la que no siente pesares (...). Soy la gentil compañera del 
noble gaucho porteño, la que conserva el cariño para su dueño", para proponer la modificación de sus versos: "Yo soy la morocha, la más combativa, la más relegada de esta población (...). Yo soy la morocha de mirada consciente, la que en su cuerpo siente discriminación..."

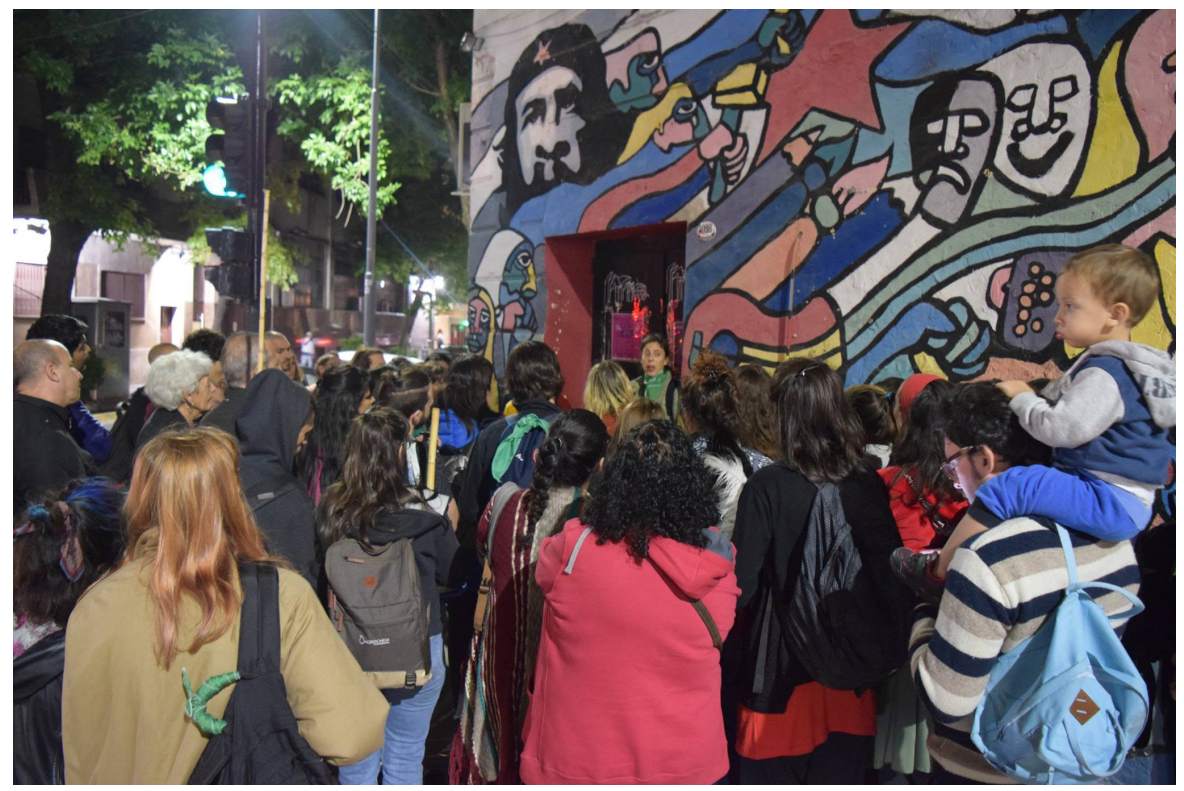

Mujeres construyen memoria, como parte del evento Los barrios tiene Memoria 2019, el 24 de marzo de 2019. Fotografía tomada por la Compañía Funciones Patrióticas.

Articulados en varias experiencias que se modifican en cada ocasión estos relatos situados tejen un entramado de subjetividades superpuestas que dejan al descubierto las operaciones de deshistorización de las prácticas culturales. No podemos dejar de mencionar, a propósito de esto, la celebración de una cultura radicante que, como explica Bourriaud, favorece "la reescritura de la Historia 'oficial' en beneficio de relatos plurales, permitiendo al mismo tiempo la posibilidad de un diálogo entre esas versiones diferentes de la Historia, para impedir que la uniformización cultural continúe propagándose". (2009: 29).

\section{Lo colectivo como modo de creación}

En oposición al individualismo y al aislamiento que propician los medios tecnológicos y los nuevos consumismos, las performances y las intervenciones urbanas configuran zonas de sociabilidad, resistencia y solidaridad comunitaria que convierten al teatro y al arte en general, en un medio privilegiado de concientización, producción y circulación de discursos.

Tanto Fin de un Mundo como Compañía de Funciones patrióticas constituyen verdaderos colectivos teatrales que comparten sus intereses y búsquedas estéticas, el proceso creativo -la exploración, la investigación, la experimentación- y la producción del evento artístico, cuya principal herramienta compositiva es la improvisación individual y grupal. La modalidad de trabajo de ambas agrupaciones se basa en la creación o colaboración colectiva que, en estos casos, enlaza la praxis artística a la política, no solo porque interpela al espectador y lo conduce a tomar una posición, sino también porque sus objetivos de reinterpretación del pasado y del presente se encuentra al servicio de la comunidad en la que se desarrolla. 
Por otro lado, si bien el trabajo conjunto implica un posicionamiento frente a la complejidad de la realidad paralelamente, se apunta a favorecer individualmente "un readueñamiento del cuerpo y de la palabra legitima, trabajando desde la simbolización y exploración crítica de la experiencia." (Adissi, Goldberg, Medina, Pazos, citado en Bang- Wajnerman, 2008: 99).

Sus tareas se despliegan al margen de las salas teatrales y de los circuitos artísticos reconocidos, no responden a modelos o parámetros genéricos ni a las convenciones teatrales tradicionales concernientes al espacio, al tiempo, a los personajes, a la creación de un universo ficcional. El acontecimiento artístico se aleja entonces de la noción de espectáculo y espectacularidad y suprime la distancia entre performer y espectador, que llevan a cabo distintas actividades y se ven implicados en una tarea de producción de nuevos sentidos y articulación de nociones identitarias. Lo que acontece entre ambos, el acto de participación, aparece como un factor fundamental, en una performance que, lejos de suponer una transmisión de saber de uno a otro, constituye "esa tercera cosa de la que ninguno es propietario, de la que ninguno posee el sentido que se erige entre los dos, descartando toda transmisión de lo idéntico, toda identidad de la causa y el efecto" (Rancière, 2017: 21).

En este sentido, los trabajos a los que aludimos reproducen las condiciones de la sociedad y la cultura actuales, que se organiza "en términos de circuitos y experimentaciones y no en términos de instalación permanente" y de un artista -un sujetoque, en su condición errante "inventa recorridos entre los signos (...) trayectos en los que "recoge fragmentos de significación" y en los que se elabora como sujeto." (Bourriaud, 2009: 59).

Cada grupo teatral conforma una microsociedad, con su particular visión del mundo y de los conflictos sociales, que expresan por medio de un lenguaje propio. En este sentido, su concepción del arte parte de una perspectiva micropolítica, centrada en la voluntad de oponer, al orden instituido, un nuevo orden de cosas propuesto desde una lógica creativa y una cosmovisión particular, que desafía las concepciones dominantes del hecho teatral, de la cultura, del quehacer político, pero también en la productividad del trabajo colectivo, en el involucramiento, en la definición del arte como acción transformadora. 


\section{Q Bibliografía}

" Augé, M. (1995). Hacia una antropología de los mundos contemporáneos. Barcelona: Gedisa.

» Bang, C. y Wajnerman C. (2010). “Arte y transformación social. La importancia de la creación colectiva en intervenciones comunitarias". Revista argentina de Psicología. (48), 89-103. Consultado el 3 de marzo de 2019 en

» Barría Jara, M. (2011). "Performance y política del acontecimiento: una crítica a la noción de espectacularidad". Aletria, 21 (1), 111-119.

» Benjamin, W. (1969/1988). Imaginación y sociedad. Iluminaciones I. Jesús Aguirre (trad), Madrid: Taurus.

» Boal, A. (2009). Teatro del oprimido. Barcelona: Alba.

»Bourriaud, N. (2009). Radicante. Buenos Aires: Adriana Hidalgo editora.

»Bourriaud, N. (2017). Estética relacional. Buenos Aires: Adriana Hidalgo editora.

"Contrahegemonia web. http://contrahegemoniaweb.com.ar/colectivo-fin-deun-mundo-cinco-anosdeintervencion-politica-desde-el-arte

»Digitum, biblioteca. https://digitum.um.es/xmlui/bitstream/10201/19592/1

" Fischer- Lichte, E. y Roselt. J. (2008). “La atracción del instante: puesta en escena, performance, performativo y performatividad como conceptos de la ciencia teatral”. Revista Apuntes. (130), 115-125

»Ginatassio, F. (2018). Colectivo Fin de un Mundo: Cinco años de intervención política desde el arte. Consultado el 12 de marzo de 2019 en

» Guattari, F. (1995). Cartografías del deseo. Gregorio Kaminsky (Comp). Buenos Aires: La marca.

» Hall, S. (2010). “El significado de los nuevos tiempos”. En Sin garantías: Trayectoria y problemáticas en estudios culturales. (pp. 485-499). Bogotá: Instituto de Estudios Sociales y Culturales, Universidad Javeriana.

"Larrañaga, J. (2001). Instalaciones. San Sebastián: Editorial Nerea

»Lobeto, C. y Circosta C. (2014). “Articulaciones entre la teoría y la práctica en en $l^{\circ}$ Ecuentro de Arte y espacio Público". En Lobeto, C. y Circosta C. (comp), Arte y espacio público. Muralismo, intervenciones y monumentos. (pp. 11-26). Buenos Aires: Facultad de Filosofía y Letras, Universidad de Buenos Aires.

"Manduca, R. "Fin de un mundo: Intervenciones escénicas urbanas entre la historia y la agenda política". telondefondo. XIII (26), 63-79.

» Mulet, T. S. y Segura Cabañero, J. (2008). Instalaciones: Intervenciones arquitectónicas, urbanas e Institucionales. Material docente. Consultado el 7 de febrero de 2019 en

»Pavis, P. (1994). “Hacia una teoría de la actuación”. En El Teatro y su recepción. Semiología, cruce de culturas y potmodernismo. (pp. 147-157). La Habana: UNEAC/ Casa de las Américas.

» Pavis; P. (2003). Diccionario del teatro. Buenos Aires: Paidós.

"Psicología. http://www.psi.uba.ar/academica/carrerasdegrado/psicologia/si- 
tios_catedras/obligatorias/066salud2/material/publicaciones/arte_y_transformacion

» Rancière, J. (2017). El espectador emancipado. Buenos Aires: Manantial.

» Richard, N. (2007). Fracturas de la memoria. Arte y pensamiento crítico. Buenos Aires: Siglo XXI.

» Rosas Mantecón, A. (1993). “Globalización cultural y antropología”, Revista Alteridades (5), 79-91.

"Svampa, M. (2008). Cambio de época. Movimientos sociales y poder político. Buenos Aires: Siglo XXI.

» Trastoy, B. (2017). La escena posdramática. Ensayos sobre la autorreferencialidad. Buenos Aires: Libretto. 